\title{
Complete genome sequence of the acidic cellulase producer Bacillus amyloliquefaciens ATC6
}

\author{
Sang Hoon Kim ${ }^{1}$, Ju Kyoung $\mathrm{Oh}^{1}$, Yong Ho Kim² and Dae-Kyung Kang ${ }^{1 *}$ \\ ${ }^{1}$ Department of Animal Resources Science, Dankook University, Cheonan 31116, Korea \\ ${ }^{2}$ Bio-Resources Institute, EASYBIO, Cheonan 31060, Korea
}

Received: Jun 15, 2020

Accepted: Jun 23, 2020

*Corresponding author Dae-Kyung Kang

Department of Animal Resources

Science, Dankook University,

Cheonan 31116, Korea

Tel: +82-41-550-3655

E-mail: dkkang@dankook.ac.kr

Copyright $@ 2020$ Korean Society of

Animal Sciences and Technology.

This is an Open Access article distributed under the terms of the Creative Commons Attribution

Non-Commercial License (http:// creativecommons.org/licenses/bync/4.0/) which permits unrestricted non-commercial use, distribution, and reproduction in any medium, provided the original work is properly cited.

ORCID

Sang Hoon Kim

https://orcid.org/0000-0001-9811-2972

Ju Kyoung Oh

https://orcid.org/0000-0002-8554-1863

Yong Ho Kim

https://orcid.org/0000-0002-4459-2744

Dae-Kyung Kang

https://orcid.org/0000-0001-9241-1250

\section{Competing interests}

No potential conflict of interest relevant to this article was reported.

Funding sources

This work was supported by a grant from the Next-Generation BioGreen 21 Program (Project No. PJ 01322303), Rural Development Administration, Korea.

Acknowledgements Not applicable.

\begin{abstract}
Here we report the complete genome sequence of Bacillus amyloliquefaciens ATC6, which produces acidic cellulase, isolated from pig feces. The genome is 4,062,817 bp in length and has a guanine-cytosine (GC) content of $46.27 \%$. Among the predicted 3,913 protein-coding genes, two glucanase genes, which are involved in lichenan and cellulose degradation, were found. This genome analysis helps clarify the mechanism involved in cellulose biodegradation and support its application for efficient use of livestock feeds.
\end{abstract}

Keywords: Acidic cellulase, Bacillus amyloliquefaciens, Feed additive

\section{INTRODUCTION}

A number of Bacillus strains reported to degrade non-digestible carbohydrates, including cellulose and hemicellulose, have been used as feed additives to increase feed efficiency [1,2]. Bacillus amyloliquefaciens ATC6 was originally isolated from pig feces, and produces acidic cellulase [3]. Here we sequenced the complete genome of B. amyloliquefaciens ATC6. B. amyloliquefaciens ATC6 was grown in Nutrient Broth (Difco, Franklin Lakes, NJ, USA) at $37^{\circ} \mathrm{C}$ for $12 \mathrm{~h}$. The genomic DNA was prepared as described previously [4], and the genome quality was checked using a spectrophotometer (UV-1601PC, Shimadzu, Kyoto, Japan). The genomic DNA of B. amyloliquefaciens ATC6 was sequenced using the PacBio RSII platform (ver. 2.0; Pacific Biosciences, CA, USA) at Macrogen. (Korea). All generated reads were de novo assembled using RS HGAP Assembly (ver. 3.0) [5]. Functional annotation was performed using the InterProScan (ver. 5.30-69.0) (http://www.ebi.ac.uk/interpro/), GO (http://geneontology.org/ page/go-database), BLAST (ver. 2.6.0+) (http://blast.ncbi.nlm.nih.gov/) with UniProt (ver. 2018_06) (http://www.uniprot.org/), and EggNOG (ver. 4.5) (http://eggnogdb.embl.de/\#/app/home) databases, and the genome was submitted to GenBank (https://www.ncbi.nlm.nih.gov/) (No. PRJNA639017).

The complete genome of strain ATC6 was 4,062,817 bp in length with a guanine-cytosine (GC) content of $46.27 \%$ (Table 1). No plasmid was detected (Fig. 1). The chromosome contained a total of 3,913 protein-coding sequences, 27 ribosomal RNAs, and 86 transfer RNAs that were annotated (Table 1). Analysis of the genomic sequences revealed that ATC6 possessed genes involved in cellulose degradation, as shown in our previous report [3]. This genome also contained genes associated with the degradation of other non-digestible carbohydrates, such as xylan and mannan. The genomic information of B. amyloliquefaciens ATC6 will help clarify the biodegradation mechanism of non-digestible carbohy- 
Availability of data and material Upon reasonable request, the datasets of this study can be available from the corresponding author.

Authors' contributions

Conceptualization: Kang DK.

Data curation: Kim SH, Oh JK, Kim YH.

Formal analysis: Kim SH, Oh JK.

Methodology: Kim SH, Oh JK, Kim YH.

Validation: Kang DK.

Investigation: Kim SH, Oh JK, Kim YH.

Writing - original draft: Kim SH, Kang DK.

Writing - review \& editing: Kang DK.

Ethics approval and consent to participate This article does not require IRB/IACUC approval because there are no human and animal participants. drates, which could increase animal feed efficiency.

Table 1. Genome features of Bacillus amyloliquefaciens ATC6

\begin{tabular}{lr}
\hline \multicolumn{1}{c}{ Attribute } & \multicolumn{1}{c}{ Value } \\
\hline Genome size (base pair) & $4,062,817$ \\
GC content (\%) & 46.27 \\
No. of contigs & 1 \\
Total genes & 4,026 \\
Protein-coding genes & 3,913 \\
tRNAs & 86 \\
rRNAs & 27
\end{tabular}

$\mathrm{GC}$, guanine-cytosine.

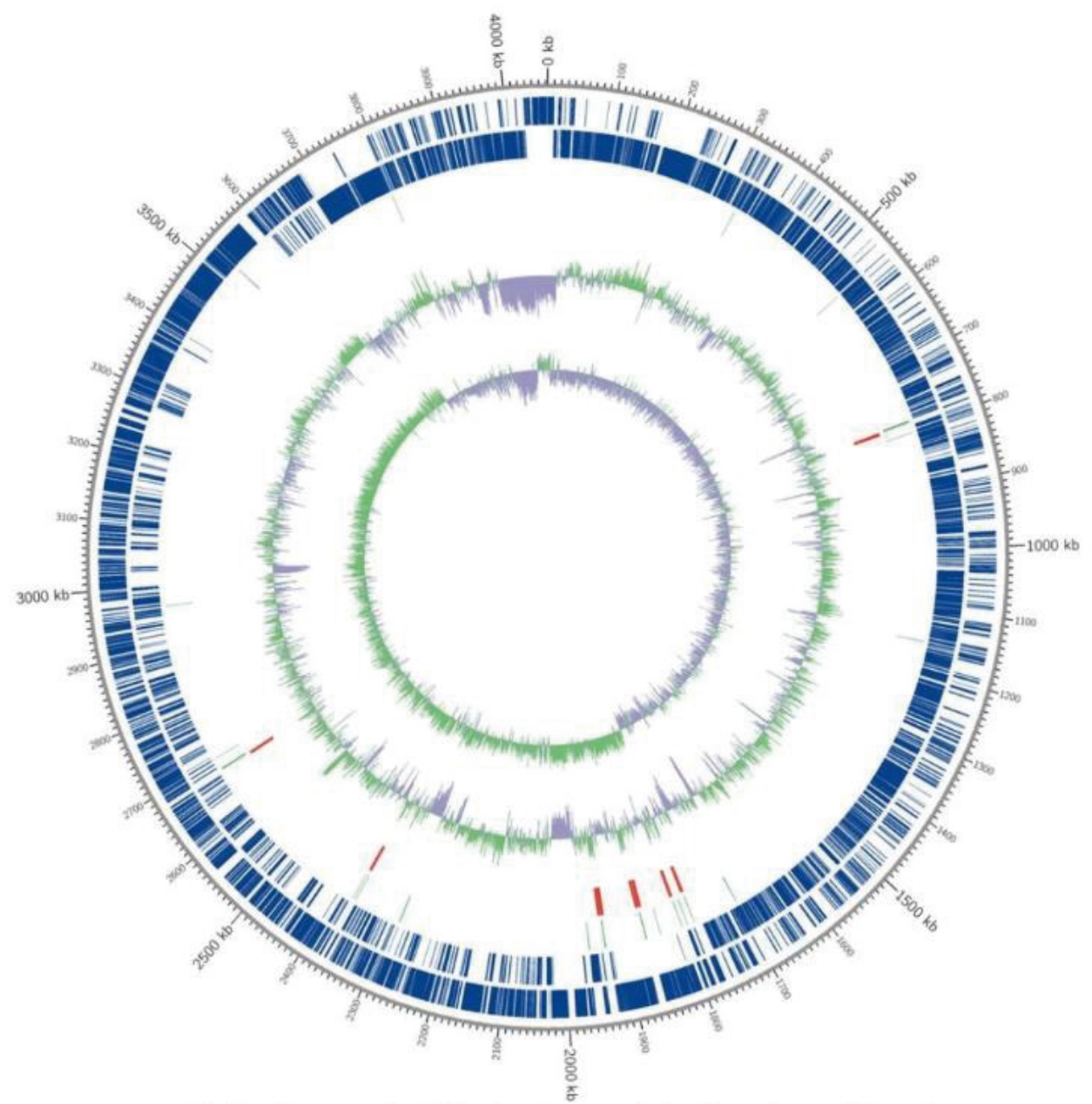

Circles illustrate the following characteristics from the outside to the center:

(1) coding sequences in forward strand, (2) coding sequences on reverse strand,

(3) Transfer RNAs (tRNAs), (4) ribosomal RNAs (rRNAs), (5) GC content, and (6) GC skew.

Fig. 1. Chromosome map of Bacillus amyloliquefaciens ATC6. GC, guanine-cytosine. 


\section{REFERENCES}

1. Lee JK, Park IK, Choi YJ, Cho J. Bacillus strains as feed additives: in vitro evaluation of its potential probiotic properties. Rev Colomb Cienc Pecu. 2012;25:577-85.

2. Bedford MR, Partridge GG. Enzymes in farm animal nutrition. 2nd updated ed. Wallingford, UK: CABI Publishing; 2010.

3. Lee SH, Chae JP, Kim MJ, Kang DK. Isolation of Bacillus amyloliquefaciens ATC6 producing acidic cellulase. J Anim Sci Technol. 2010;52:65-70. https://doi.org/10.5187/ JAST.2010.52.1.065

4. Valeriano VDV, Oh JK, Bagon BB, Kim HB, Kang DK. Comparative genomic analysis of Lactobacillus mucosae LM1 identifies potential niche-specific genes and pathways for gastrointestinal adaptation. Genomics. 2019;111:24-33. https://doi.org/10.1016/j.ygeno.2017.12.009

5. Chin CS, Alexander DH, Marks P, Klammer AA, Drake J, Heiner C, et al. Nonhybrid, finished microbial genome assemblies from long-read SMRT sequencing data. Nat Methods. 2013;10:563-9. https://doi.org/10.1038/nmeth.2474 
